\title{
Bilateral Oculomotor Palsy in Tuberculous Rhomboencephalitis-A Rare Presentation
}

\author{
Paromita Dutta ${ }^{1}$ Vaibhav Nagpal ${ }^{1} \quad$ Kamlesh Anand $^{1}$ \\ ${ }^{1}$ Guru Nanak Eye Centre, Maulana Azad Medical College, New Delhi, \\ India
}

J Neurosci Rural Pract:2021;12:217-218

Rhomboencephalitis is an uncommon form of neurotuberculosis $(<5 \%$ of cases) and carries a poorer prognosis in terms of mortality and neurological sequelae. ${ }^{1}$ We report a case with bilateral third nerve palsy in a patient with tuberculous rhomboencephalitis (TR) and adverse outcome.

A 24-year-old male presented with subacute onset, bilateral, pupil involving oculomotor palsy, without visual impairment ( - Fig. 1). He also had associated headache, low-grade fever, vomiting, and hypersomnia. The patient was afebrile, conscious and oriented, extremely somnolent, and otherwise with no neurological signs other than nuchal rigidity. Direct and consensual pupillary responses were absent along with accommodation paralysis. Fundus examination was unremarkable.

A tuberculin skin test was highly positive, but a chest radiograph showed no signs of pulmonary tuberculosis. Blood investigations were unremarkable except for mild anemia (hemoglobin-9.9 g/dl) and slightly elevated erythrocyte sedimentation rate $(25 \mathrm{~mm} / \mathrm{h})$. Serum HIV test was negative.

Cerebrospinal fluid (CSF) analysis showed a cell count of 35 cells $/ \mathrm{mm}^{3}$ with $60 \%$ lymphocytes and $40 \%$ polymorphs, low glucose ( $40 \mathrm{mg} / \mathrm{dl}$ ), CSF/blood glucose ratio of 0.30 , and elevation of protein (130 mg/dl). CSF acid fast bacillus (AFB) stain was positive.

MRI of brain revealed multiple discrete to conglomerated ring-enhancing lesions in bilateral cerebellar hemispheres, vermis, pons and cerebral cortex with mild perilesional edema, which was suggestive of inflammatory granulomas. Exudates with few ring-enhancing lesions were seen in the basal cistern (-Fig. 2). Bilateral lateral, third, and fourth ventricles were dilated, along with periventricular ooze, indicative of communicating hydrocephalus. There were no midbrain lesions or border zone encephalitis.

A diagnosis of TR with hydrocephalus was made. The patient was started on antituberculosis therapy (3HRZE/9HRZ) along with intravenous $20 \%$ mannitol $100 \mathrm{~mL}$ twice a day for 3 days, acetazolamide $250 \mathrm{mg}$ four times a day, pyridoxine
Address for correspondence Paromita Dutta, MD, DNB, Flat 501, Tower 11, Lotus Panache, Sector 110, Noida-201304, India (e-mail: mitad_4@yahoo.com).

$40 \mathrm{mg}$ once daily, prednisolone $50 \mathrm{mg}$ once daily, and levetiracetam $500 \mathrm{mg}$ twice a day. A neurosurgery consult was advised. However, after 5 days of initiating treatment, the patient died after developing intractable breakthrough seizures and aspiration pneumonia.

Associated cranial nerve $(\mathrm{CN})$ palsy is an important feature to differentiate tuberculous meningitis (TBM) from other causes of meningitis. TBM patients with $\mathrm{CN}$ palsy have a higher incidence of altered sensorium. ${ }^{2}$ The oculomotor nerve is most commonly affected in TBM, usually unilaterally. This narrow caliber nerve traverses a long intracranial course and is divided into four segments: central, cisternal, cavernous, and orbital. In basal meningitis, ischemia (secondary to vasculitis or nerve rootlet entrapment by exudates) affects the cisternal part of oculomotor nerve while emerging from the midbrain in the interpeduncular fossa. ${ }^{3}$ The clinical picture may be that of partial or complete third nerve palsy, with or without pupillary involvement. In contrast to published studies, our patient had bilateral complete third nerve palsy with involvement of pupillary fibers, indicating a severe grade of basal meningitis.

Absence of papilledema in spite of severe hydrocephalus may be due to severe and widespread arachnoid granulations, preventing transmission of raised intracranial pressure to the optic nerve sheaths. In fact, papilledema may be seen in only $25 \%$ of patients with TBM. ${ }^{4}$

Medical management may be considered in cases with communicating hydrocephalus, in milder grades of hydrocephalus, and MRC (British Medical Research Council) stage 2 or 3 TBM with hydrocephalus. ${ }^{5}$ Our patient was managed accordingly, keeping an alternative of a secondary/delayed surgical intervention (ventricular shunt).

Rhomboencephalitis may have a wide spectrum of presentation, which may or may not include cerebellar signs. Bilateral third nerve palsy is an indicator of a more severe form of TBM. Delayed presentation worsens an already poorer prognosis. Improved awareness to seek medical advice early might help reduce mortality and morbidity.
DOI https://doi.org/ $10.1055 / \mathrm{s}-0040-1721168$ ISSN 0976-3147. (c) 2020. Association for Helping Neurosurgical Sick People.

This is an open access article published by Thieme under the terms of the Creative Commons Attribution-NonDerivative-NonCommercial-License, permitting copying and reproduction so long as the original work is given appropriate credit. Contents may not be used for commercial purposes, or adapted, remixed, transformed or built upon. (https://creativecommons.org/licenses/by-nc-nd/4.0/)

Thieme Medical and Scientific Publishers Pvt. Ltd. A-12, 2nd Floor, Sector 2, Noida-201301 UP, India 


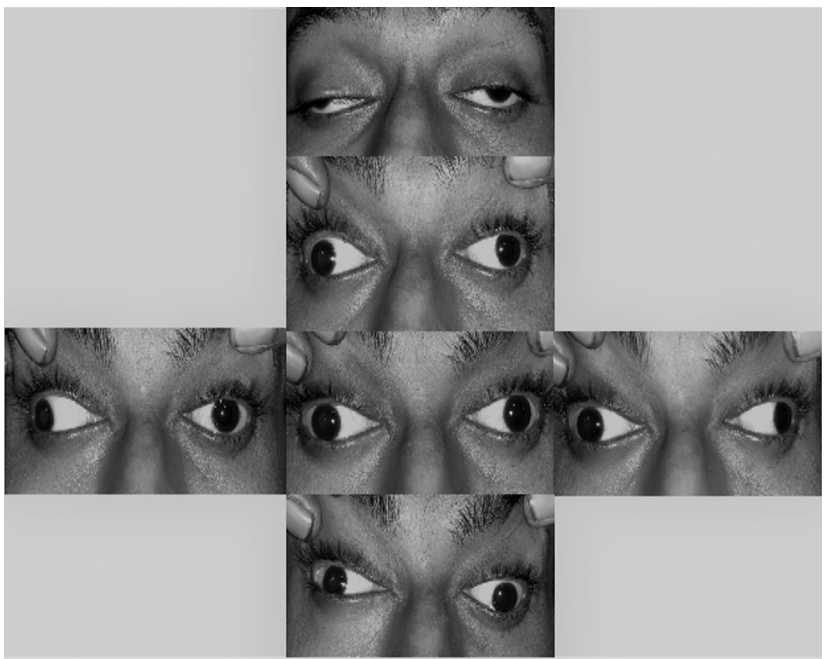

Fig. 1 Bilateral severe ptosis with severe limitation of ocular motility in all gazes except abduction. Asymmetric bilateral third nerve palsy.

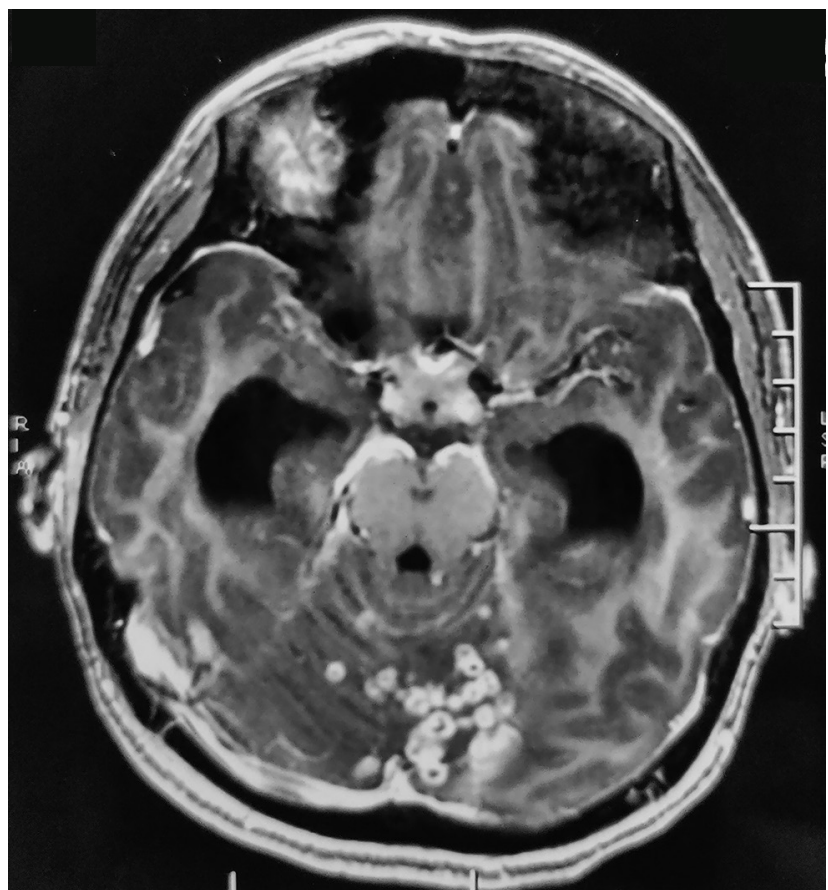

Fig. 2 T1-weighted, contrast-enhanced image (axial section) shows multiple discrete to conglomerated ring enhancing lesions in bilateral cerebellar hemispheres, vermis, pons, scattered along cerebral hemispheres, with mild perilesional edema; exudates in the perimesencephalic cistern; dilated bilateral lateral, third and fourth ventricles.
Note

Informed consent has been taken from the patient's guardian.

\section{Funding}

None.

\section{Conflict of Interest}

None declared.

\section{References}

1 Khatri GD, Krishnan V, Antil N, Saigal G. Magnetic resonance imaging spectrum of intracranial tubercular lesions: one disease, many faces. Pol J Radiol 2018;83:e524-e535

2 Li X, Ma L, Zhang L, Wu X, Chen H, Gao M. Clinical characteristics of tuberculous meningitis combined with cranial nerve palsy. Clin Neurol Neurosurg 2019;184:105443

3 Liang C, Du Y, Lin X, Wu L, Wu D, Wang X. Anatomical features of the cisternal segment of the oculomotor nerve: neurovascular relationships and abnormal compression on magnetic resonance imaging. J Neurosurg 2009;111(6):1193-1200

4 Hanna LS, Girgis NI, Yassin MW, et al. The incidence of optic atrophy in meningitis. Bull Ophthalmol Soc Egypt 1978;71(75): 113-118

5 Rajshekhar V. Management of hydrocephalus in patients with tuberculous meningitis. Neurol India 2009;57(4):368-374 